\title{
What Scientists Do: Engaging in Science Practices through a Wonder- Framed Nature Study
}

\author{
Steph N. Dean ${ }^{1 *}$, Andrew Gilbert ${ }^{1}$ \\ ${ }^{1}$ College of Education and Human Development, George Mason University, UNITED STATES \\ *Corresponding Author: sdean20@gmu.edu
}

Citation: Dean, S. N., \& Gilbert, A. (2021). What scientists do: Engaging in science practices through a wonder-framed nature study. Interdisciplinary Journal of Environmental and Science Education, 17(4), e2255. https://doi.org/10.21601/ijese/11136

\begin{tabular}{ll}
\hline ARTICLE INFO & ABSTRACT \\
\hline Received: & Despite recent reforms concerning how students engage in science, there have been significant
\end{tabular}

26 April $2021 \quad$ challenges for educators seeking to consistently implement science practices within the classroom This study considered science practices within a wonder-framed nature study as one possible way for educators to support students as they take on the role of scientists. We interviewed twenty

Accepted:

7 June 2021 students in Grades 3 through 5 who had participated in wonder journaling sessions outdoors that led to an investigative project and presentation. The evidence suggests that students strongly engaged in investigative science practices, and that they also experienced opportunities for sensemaking and critiquing practices. Through a qualitative data analysis, four main themes emerged that provide insight into the experiences of the students within the study: joy, community, autonomy, and challenges. The data indicate that wonder is an authentic and viable route towards the implementation of the science practices within an elementary school setting. The implications of this study are considerable and offer strategies for educators seeking to incorporate science practices in an authentic way that integrates both wonder and outdoor learning.

Keywords: science practices, NGSS, wonder, outdoor learning, nature journaling

\section{INTRODUCTION}

According to the National Science Teaching Association (NSTA, 2014), science practices "describe behaviors that scientists engage in as they investigate and build models and theories about the natural world..." (para 1). Namely, science practices are what professional scientists do and what we want student scientists to do. Students engaging in the science practices require skills as well as specific knowledge that relates to each practice (NGSS, 2013). The science practices include both cognitive outcomes and abilities (Bybee, 2014) with the end goal of making conceptual progress through science as a way of knowing (Antink-Meyer \& Meyer, 2016). NGSS (2013) identifies eight specific practices that are essential to students learning how scientific knowledge develops.

Coupled with a rigorous curriculum, engaging students in science practices leads to improved student outcomes (Merritt et al., 2018). Yet despite reforms on how students should be engaging in and doing science, this is not consistently being implemented in school classrooms (Kang et al., 2018; Merritt et al., 2018). Teachers often struggle with how to authentically incorporate the science practices, particularly in earlier grades that require a precise level of task complexity (Merritt et al., 2018). The studies that have investigated NGSS science practices typically focus on teacher perceptions, including competencies, misconceptions, and selfefficacy (see Antink-Meyer \& Meyer, 2016; Kang et al., 2018; Kelley et al., 2020). The purpose of this qualitative study is to explore the ways in which students engage with the science practices through a wonder-framed nature study. We looked beyond simply quantifying the practices that emerged from the data and sought to investigate student experiences with these practices. We also chose to look solely at science practices, not engineering

Copyright (C) 2021 by Author/s and Licensed by Veritas Publications Ltd., UK. This is an open access article distributed under the Creative Commons Attribution License which permits unrestricted use, distribution, and reproduction in any medium, provided the original work is properly cited. 
practices, although we recognize their equal importance and the need for further study in both areas.

\section{LITERATURE REVIEW}

The current global pandemic is a compelling reminder of the importance of preparing scientifically literate future generations to address the pressing issues we face as a society. Yet in order to learn how to understand and explain the natural world, students need ongoing opportunities to engage meaningfully in the science practices (Kawasaki \& Sandoval, 2019). By looking at the concept of wonder positioned alongside of the science practices, we present a framework to our study that is driven by student autonomy as scientists (Reeve et al., 2014).

\section{Wonder}

As teachers, we have seen so many children turned off to science when undertaken in traditional, teacher-centered ways that are overly focused on skills-driven pedagogy. Although skill building is important, solely developing those skills will not inherently inspire children to engage with and learn about science (Forbes \& Skamp, 2014). Ultimately, participating in authentic science tasks is about the pursuit of knowledge, facing daunting challenges, and/or solving the unknowns that fascinate us. These are often difficult, frustrating and time-consuming approaches to solve problems. In his book Letters to a Young Scientist, the award-winning naturalist E.O. Wilson (2013) proclaimed that "The ideal scientist thinks like a poet and only later works like a bookkeeper" (p. 74). Our contention is that we must help children learn to emotionally engage with the questions that vex them before we ask them to work like engineers and scientists. We consider that by engaging students with their wonderings can act as an introductory step toward making sense of practices scientists use in their investigations.

Scientists have continually articulated the central importance of wonder as an integral element of their work - one that drives them toward the exploration of the unknown and represents the heart of joyous experience (Hadzigeorgiou, 2014). Researchers have synthesized several aspects of wonder-infused pedagogy as a means for teachers to enact in classrooms. These processes are generally comprised with the creation of an environment where unfettered exploration is necessary, experiences are connected to emotion and empathy, effort is made to evoke wonder from observations, and the process is organic and led by the interest of children (Hadzigeorgiou, 2016; Milne, 2010; Trotman, 2014). Building from a place of wonder can help to frame both a desire to answer a question, build a way to test that question, and provide the emotional connection to pursue those answers even when it becomes difficult (Gilbert \& Byers, 2017). This emotional connection to content is an area that is often overlooked in the science classroom since it is not easily quantified nor easily articulated as a pedagogical process (Gilbert, 2020). However, as Washington (2019) argued, engaging children with the nature world can serve as a powerful catalyst for wonder.

In order for science teachers to approach wondering with children, they must not only make space for wondering within their pedagogy, but they must also actively work to evoke wonder with their students (Hadzigeorgiou, 2014). Teachers wishing to evoke wonder must facilitate students to see the extraordinary in the natural environment that surrounds them. This can be done by using specific questions that are designed to deepen thinking towards the object and reflect on the scientific possibilities, while also remaining open to the beauty of the phenomena itself (Hadzigeorgiou, 2020). This evoking of wonder invites children to think about how the science practices and evidentiary claims represent an invitation to think beyond the typical limits of the classroom. In this study, we explored the potential of evoking wonder with children in the outdoors as a means to facilitate children enacting the practices of science.

Glăveanu (2020) defined the wide-ranging nature of wonder "is connected to not knowing, wanting to know, getting to know and everything in between. It is deeply emotional, but still bound to thinking" ( $p$. 22). Evoking wonder as means to frame science content can have a significant impact on student achievement (Hadzigeorgiou, 2012). Using wonder as a pedagogical tool taps into the uniquely human process that connects our intense need to know through scientific practices such as observing, data gathering, hypothesizing, etc. A pedagogy of wonder focuses on initially seeking questions as opposed to answers through open wondering as a means to connect learners emotionally, intuitively, and cognitively to the world around them and connecting to the practices associated with scientific inquiry (Gilbert \& Byers, 2020). Consequently, students are encouraged to dig deeply into their questions that arise as the engage in the natural world. Hadzigeorgiou (2012) demonstrated that following one's sense of wonder led directly to increased achievement and understanding of key science content. The goal is to use those wonderings as a prerequisite to build desire to take on the difficult skill building related to problem solving, data collection, and hypothesizing that lies at the heart of 
Table 1. NGSS Science Practices Grouped into Investigating, Sensemaking, and Critiquing (McNeil et al., 2015).

\begin{tabular}{lll}
\hline Investigating Practices & Sensemaking Practices & Critiquing Practices \\
\hline 1. Asking Questions and Defining & 2. Developing and Using Models & 7. Engaging in Argument from Evidence \\
Problems & 4. Analyzing and Interpreting & 8. Obtaining, Evaluating, and \\
3. Planning and Carrying Out & Data & Communication Information \\
Investigations & 6. Constructing Explanations and & \\
$\begin{array}{l}\text { 5. Using Mathematics and } \\
\text { Computational Thinking }\end{array}$ & Designing Solutions & \\
\hline
\end{tabular}

enacting science and builds a positive disposition towards the practices of science.

\section{Science Practices}

When NGSS was released in 2013, the conceptualizations of science practices required teachers to change how they organized instruction, necessitating a significant shift in the way science is taught (Kawasaki \& Sandoval, 2020). The intention was to transition students away from merely learning about science ideas to figuring out science ideas (Cherbow et al., 2020). The ultimate goal of the science practices is for students to be able to mirror what scientists do - systematically explain, model, and provide evidence for the natural world (Cherbow et al., 2020; Pasley et al., 2016). Children naturally investigate the world around them and build on their ideas over time; there is a deliberate process involved in how they make sense of their world (Lowell et al., 2021). Within the framework of wonder, it is even more imperative to provide students with the opportunities to pose questions about natural phenomena and then determine how to answer these ponderings. McNeill et al. (2015) have grouped NGSS' eight science practices into three categories investigating, sensemaking, critiquing - as a helpful way for educators to consider the main concepts and purposes. Table 1 shows how McNeill et al. (2015) represented one possible way of clustering the eight science practices in order to consider their occurrence within classroom instruction.

Although NGSS describes what each practice should look like within a specific grade, there is very little guidance as to how these practices might be enacted within a classroom (Pasley et al., 2016). Science instruction is still often teacher-driven and consists of content memorization (Cherbow et al., 2020). Even with rubrics and assessment tools, it is difficult to define what NGSS-alignment looks like (Lowell et al., 2021). In 2017, McNeill et al. (2018) posited that schools and personnel were not ready to enact the reforms put forth by NGSS, explaining how both teachers and principals misconstrue inquiry with hands-on experiments rather than authentic science practices. Science is not simply about delivering content, but about leading students to effectively engage with a discipline (Kawasaki \& Sandoval, 2019). Student choice is a critical piece of encouraging students to make meaningful selections regarding the scientific work that they do (Duschl \& Bybee, 2014; Kawasaki \& Sandoval, 2019). This requires sufficient amount of time as well as a balance between teacher and student-led investigations with scaffolding remaining a critical part of this process (Merritt et al., 2018).

In response to the paucity of research on NGSS' science practices, Pasley et al. (2016) developed a primer that describes in detail what students should be doing when engaged with the science practices, providing comprehensive examples. They posit that the science practices often have overlaps and are used simultaneously (Pasley et al., 2016). Other educators/researchers have published articles to offer support to science teachers wishing to enact the science practices in an authentic manner. For instance, Benedict-Chambers and Fortner (2019) propose asking "the right kind of questions" as a way to engage students in scientific thinking and to integrate science practices with content (p. 50). In addition, making and recording scientific observations is a fundamental component of the science practices that can be used for future evidence and argumentation (Arias \& Davis, 2016). Nyman and St. Clair (2016) work with preservice teachers to model instruction that integrates the science practices and draws attention to the non-linear nature of science experiments. Although there are articles which address the challenges of implementing NGSS science practices, there is not a great deal of research that focuses on the realization of what it means to be a scientist as a student. Our study seeks to coalesce the science practices within the context of wonder as one possible way to equip students to be and actas scientists.

\section{THEORETICAL FRAMEWORK}

When considering both wonder and science practices, we recognize the value of autonomysupportive instruction, a theory which supports the validation of student experiences and freedom to make personal choices (Baker \& Goodboy, 2018). Autonomy-supportive instruction places student 
perspectives at the forefront and embraces learners' ideas, thoughts, emotions, and suggestions (Alley, 2019). Research has shown that autonomysupportive instruction brings about high intrinsic motivation in students and leads to persistence with learning tasks (Baker \& Goodboy, 2018). In regards to the science practices, autonomy-supportive instruction gives students agency, allowing them to be responsible for their own epistemic production and dialogue with others regarding their scientific knowledge-building process (Kawasaki \& Sandoval, 2020). Educators with an autonomy-supportive instruction style take a neutral stance towards student initiative rather than being strongly prescriptive about what students should think or feel (Reeve et al., 2014).

It was our desire to facilitate a meaningful and enriching learning environment for students to experience a wonder-framed nature study that was driven by their own natural sense of curiosity. If the purposes of the science practices are for students to mirror what scientists do (see Bybee, 2014), we posit that learners need the opportunity to make decisions like scientists and to autonomously engage in the practices. Other researchers have suggested similar approaches within science education, such as the concept student authority (Engle \& Conant, 2002) as well as epistemic agency (Lowell et al., 2021; Kawasaki \& Sandoval, 2019). We are specifically using autonomy-supportive instruction as our framework because it enables us to continually examine our own actions as both educators and researchers. We are the ones choosing to support students in their autonomy throughout the learning experience, meaning that we are also the ones who must step back and let students lead. When designing the study, we provided opportunities for student choice, rather than pressuring students into a particular behavior or coercing them to think in a way aligned with the science practices. Based on prior experiences with adults, we suspected that science practices might naturally emerge during this particular context, yet we chose not to control the direction of student decisions or behaviors. According to Jang et al. (2010), teacher-provided structure is an important component of autonomysupportive instruction, so we incorporated basic parameters into the wonder-framed nature study in hopes of further increasing student engagement. Recognizing that the science practices require teacher guidance (Pasley et al., 2016), we provided "clear and detailed expectations and instructions", offered support, and gave feedback to students as a way to scaffold the wonder-framed nature study as well as structure student autonomy (Jang et al., 2010, p. 598). The methods section below provides more details as to how we set up the opportunities for student to engage with wonder in a natural environment.

\section{Research Questions}

Our study's purpose was to explore what it means to be a student scientist as realized through the science practices. In order to move towards this purpose, the following research questions guided our inquiry:

- In which ways did elementary students enact science practices during the wonder-framed nature study?

- How do elementary students engage with the science practices through wonder?

\section{METHODOLOGY}

Since our goal within this research study was exploration, we chose qualitative methodology that would enable us to study a phenomenon - science practices and wonder - in an open-ended way (Johnson \& Christensen, 2014). From an interpretivist perspective, we wanted to describe, understand, and interpret (Merriam \& Tisdell, 2016) how elementary students engaged in the science practices within the wonder-framed nature study. We first describe the setting and participants of our study, before moving on to outline the data sources and analysis.

\section{Wonder Setting and Participants}

This study took place at a private elementary school in a mid-Atlantic suburban area. The context of this study revolved around wonder sessions which were weekly 20-minute allotments in which students had opportunities to wonder in an outdoor environment. The school property comprises a large field used for sports as well as a two-acre tract of wooded land. This context was essential in our efforts to evoke wonder through exploration within the natural world. The teacher intentionally utilized items and questions that would evoke reactions of wonder within her students before setting them out to wander and observe the surrounding woods. The concept of wonder was introduced by asking students "What is wonder?" After children shared their ideas, the teacher provided them with a tray of various items found in the local woods to consider and evoke wondrous thinking (seed pods, turtle shell, praying mantis egg sack, etc.). After this initial effort to evoke wonder, students were provided wonder journals to record their observations, questions, or contemplations through drawings or words. In line with autonomy-supportive instruction, students had 
significant freedom to wonder about what interested them after the teacher initiated the activity with some sort of framework. For example, one week the teacher encouraged students to wonder about something they found on the ground. Another week, the students were taken to a part of the school property that they were less familiar with.

There were 20 participants, Grades 3 through 5, who participated in the study. The wonder sessions lasted for eight weeks, at the end of which students chose one of their wonder questions to further investigate and then share through a presentation styled similarly to a science fair. We received consent from a parent/guardian as well as assent from each child who participated. The head of school also gave permission for us to observe the students engaging in wonder during their weekly outdoor sessions.

\section{Data Sources and Analysis}

The primary data sources we used were interviews and observations, although a teacher journal and student work (journals/posters) were also considered. We interviewed students in small groups, with four to six students in each group. These interviews were recorded and then transcribed. The second author also took notes during in-person observations of the sessions, and both authors took pictures or scans of student work.

We closely mirrored the data analysis approach of Braun and Clarke (2006) since the suggested phases of their thematic analysis were appropriate for this project. After transcribing the interview, phase one involved separately highlighting evidence of the science practice within all of the data sources in order to narrow down the data that pertained to our area of inquiry. We sorted these science practices into the three categories suggested by McNeil et al. (2015): investigating, sensemaking, and critiquing. We then entered the phase two, generating initial codes by focusing on features of short data segments within the portions of data connected to science practices. We used MaxQDA to systematically search for themes within science practice data, taking an emic approach. For example, we kept initial codes in the first-person language staying close to students' own words, such as "I thought about inquiry step-by-step."

After going through the data independently, we compared initial codes and made adjustments. We checked each other's groupings of the three categories (see McNeil et al., 2015) and discussed any disparities within our understanding of the data. As we organized these many codes, we moved into phase three which focused on searching for broader categories. We rearranged the codes we had previously uncovered, finding sets within the patterns and relationships between various levels.
We created parent categories in MaxQDA and then sorted through the data codes, placing them in a corresponding category. Phase four in Braun and Clarke's (2006) thematic analysis process involves creating more comprehensive themes and then reviewing these by going back to the data set. We found it helpful to return to our original research questions and reflect upon our comprehensive themes.

\section{Considerations}

As teachers and researchers, we were interested in how wonder and wondering in a school-based context might provide insights into how children enact science practices during their engagement with the environment. This small-scale study was not meant to be generalizable based on both the limited sample size and the non-randomized selection of participants. Since the possible connection between science practices and wonder has not been attempted, we crafted this small-scale approach to investigate this unknown space. We also deemed that a private school context provided a meaningful laboratory to investigate this connection since the school had less constraints due to district mandated standards, curricula, or testing. We do not deny that this is a major limitation for those working in public school contexts, but in order to best investigate the research questions, we wanted to strip away many of those factors that constrain teachers in other contexts. Consequently, as researchers we will need to deeply consider how these approaches might be carried out in public school contexts in which teachers and administrators have less autonomy to enact a similar wonder-framed nature study.

\section{FINDINGS}

\section{Evidence of the Science Practices}

Our first research question concerned the ways in which students enacted science practices during the wonder-framed nature study. In this section, we address the evidence found within the student interviews alongside of other data sources, such as journals and posters. Table 2 illustrates a sample of the great variety in sources of student wonder as organized into categories. Students also demonstrated a variety of approaches to their wonderings, often demonstrating curiosity regarding the history of an object, a related cause-and-effect, or its connection to the rest of nature. When sorting the data into investigating, sensemaking, and critiquing, there were many times in which we noticed an overlap, demonstrating how the practices are often used simultaneously as Pasley et al. (2016) determined. Thus, it's important to consider the 
integral nature of the science practices despite the distinct way we have chosen to group them.

\section{Investigating Practices}

The evidence we found connected to the investigating practices was substantial. Students mentioned many times within the interviews how they were driven by wonder to ask questions and then determine how they could find the answer to their inquiries. Some students even explicitly mentioned how questions drive science as part of meaningful learning.

\section{-You can't really learn without asking questions.}

The journal entries that students developed also represent the important practice of asking questions. Figures $1 \mathrm{a}$ and $1 \mathrm{~b}$ show sample journal entries that represent student questions within the wonderframed nature study. There were also students who discussed the scientific planning process they went

Table 2. Selected examples for sources and descriptions of evoked wondering

\begin{tabular}{lll}
\hline Category & $\begin{array}{l}\text { Sources of } \\
\text { wonder }\end{array}$ & Descriptions of evoked wonder \\
\hline Animals & $\begin{array}{l}\text { Mammals: } \\
\text { squirrel, fox, } \\
\text { rabbit }\end{array}$ & $\begin{array}{l}\text { Focus group: "I wondered how sharp a squirrel's teeth are...it was really fun. We got } \\
\text { more interested in squirrels." }\end{array}$ \\
& $\begin{array}{l}\text { Insects: ant, } \\
\text { millipede, moth, } \\
\text { worm, spider, } \\
\text { mosquito }\end{array}$ & $\begin{array}{l}\text { Focus Group: "Ants, when they make holes in things how does their house stays up? } \\
\text { Because it's like dirt can crumble down and you have to really pack it so it will stay." }\end{array}$ \\
& $\begin{array}{l}\text { How many birds were calling? What were they telling each other? Can different kind } \\
\text { of birds still communicate to each other and know what they are saying? Why did they } \\
\text { stop chirping when we came in? Do they ever get tired of talking/chirping? }\end{array}$
\end{tabular}

Trees Trunk Focus group: "When me and J found the leaf with the little eggs on it, we got really
excited about it."

Stump/log

Hole in tree

Focus group: "You can wonder about why is that tree different than this tree...and you know what trees are, but it's a different shape, so you get to actually, some kids just go outside for like, just running and playing. But this helps you to actually think about what you're looking at and what you're surrounded by."

Leaves

Focus group: "Well, one thing that I wondered was. I know that, like, we, so we breathe in oxygen, and then we breathe out carbon dioxide...I always wondered, I've kind of always thought, cause like trees produce oxygen, but they use the carbon dioxide too. Like they kind of almost breathe in carbon dioxide. Like, how does that work? Cause Bark they kind of like breathe it in. Like, we breathe it out, and we breathe it in. And they make oxygen, we breathe that in.

$\begin{array}{lll}\text { Abiotic } & \text { Rocks } & \text { Wonder journal excerpt. I wonder how many rocks are in a one-foot square space in } \\ \text { Nature } & \text { Dirt } & \text { the creek? }\end{array}$

Focus group: "Like one time, on the dirt, I saw this little tiny piece of sap that was like dry."

\begin{tabular}{lll}
$\begin{array}{l}\text { Human } \\
\text { Artifacts }\end{array}$ & $\begin{array}{l}\text { Bricks } \\
\text { Glass } \\
\text { Litter }\end{array}$ & $\begin{array}{l}\text { Focus group: "We found charred bricks and like where it was charred, as if burned. } \\
\text { What I was wondering was: Why was it there? When did it burn down? And why did it } \\
\text { burn down? Those were the three main questions I had about it." }\end{array}$ \\
& $\begin{array}{l}\text { Focus group: "If you're touching a tablet or a phone, how does it know where you're } \\
\text { touching, if you're touching? Cuz there's a screen of glass in between. How does it feel } \\
\text { that? “ }\end{array}$ \\
\hline $\begin{array}{l}\text { Other } \\
\text { Plants }\end{array}$ & $\begin{array}{l}\text { Vines } \\
\text { Moss } \\
\text { holly berries } \\
\text { Grass }\end{array}$ & $\begin{array}{l}\text { Focus group: "Sometimes yournal: Vines. I wonder what makes the vines get so sturdy? What are they } \\
\text { there's nothing special about it.' But if you go really close, you can see really, really } \\
\text { interesting stuff." }\end{array}$ \\
\end{tabular}




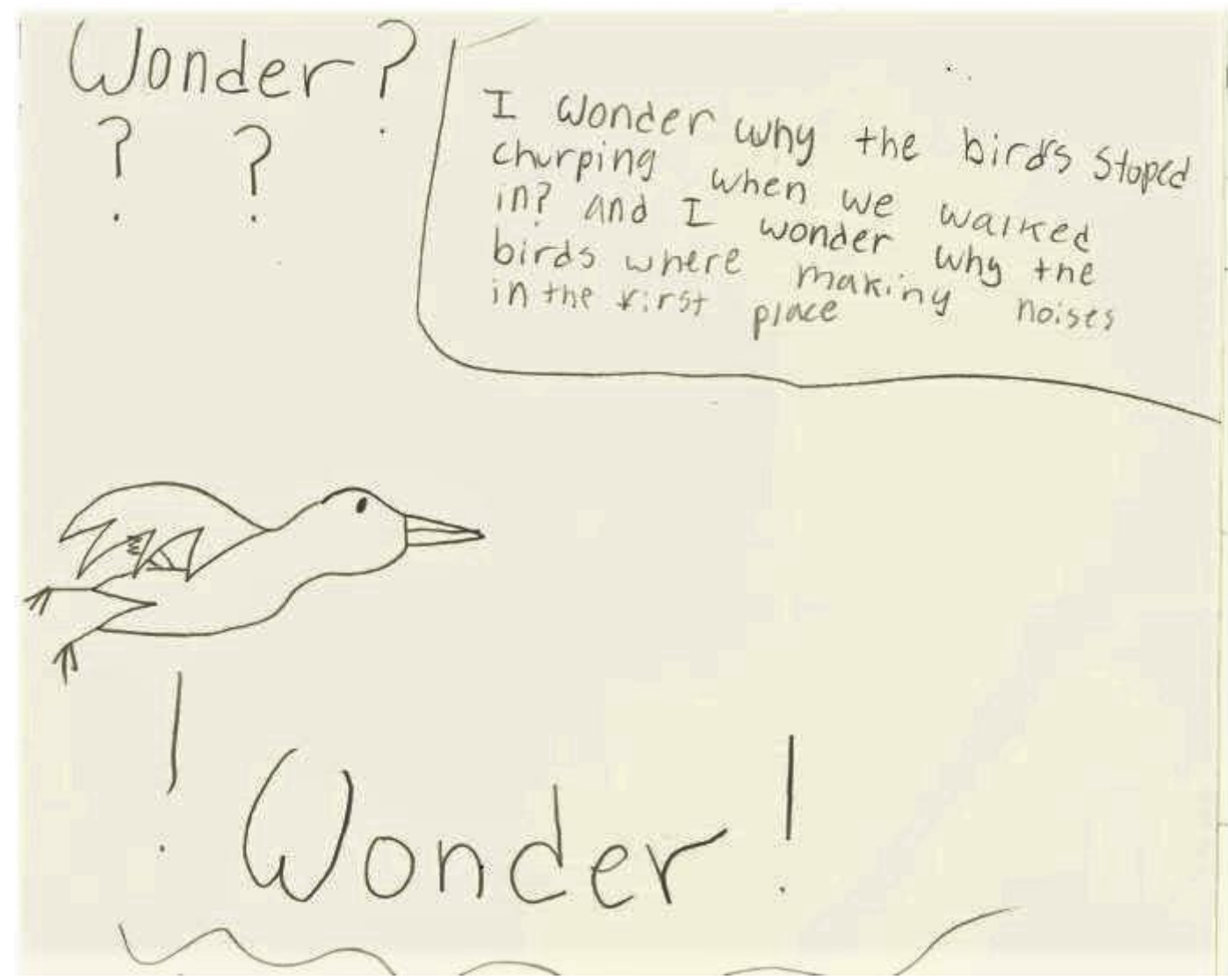

Figure 1a. Journal entry representing student questions (Wonder! I wonder why the birds stopped chirping when we walked in? And I wonder why the birds were making noises in the first place?)

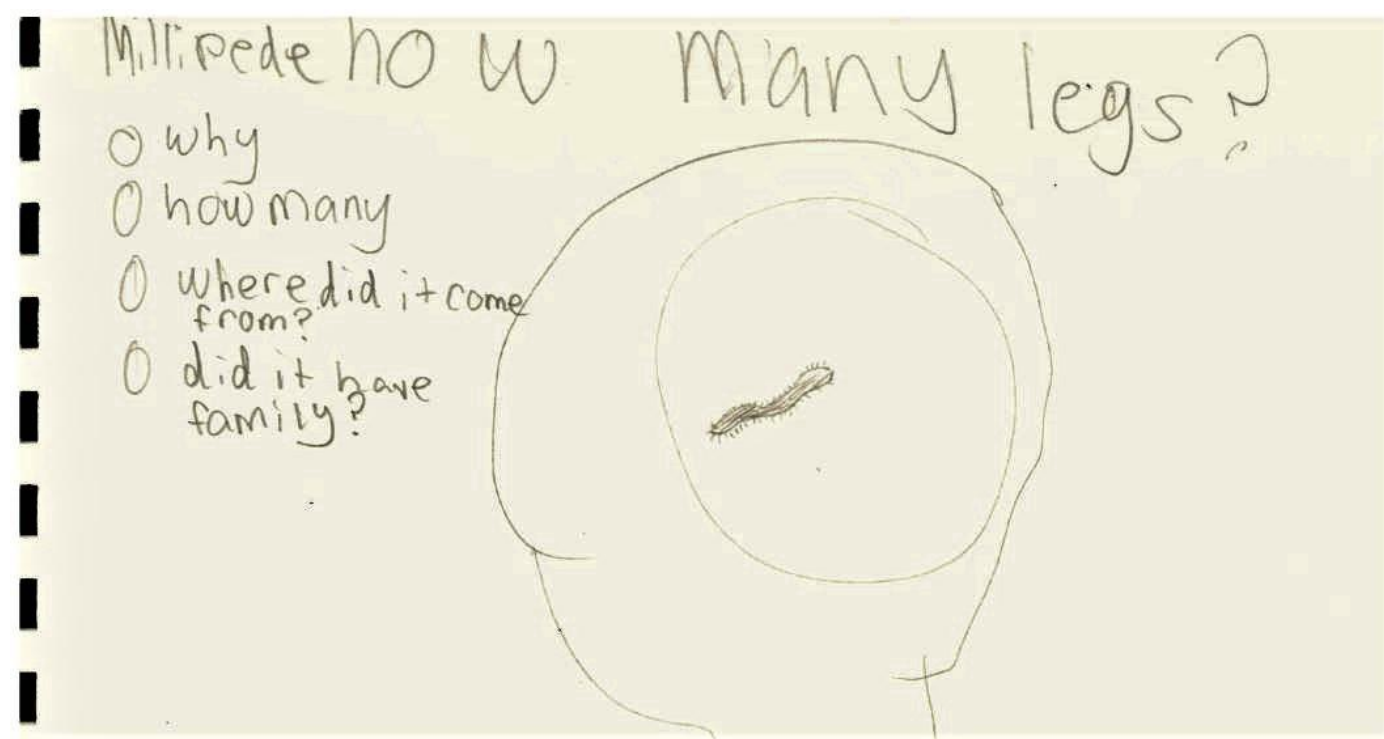

Figure 1b. Journal entry representing student questions (Millipede, how many legs? Why? How Many? Where did it come from? Did it have family?)

through and the computational thinking they employed.

- And then we had to compile all that information, make a chart on the computer. It was a process, but it was fun.
The evidence in the data indicate that students engaged in the investigating practices when they were given the opportunity to wonder and to further explore one of these wonderings with autonomy.

\section{Sensemaking Practices}

The sensemaking practices were also evident within our data, but to a different extent than the 
investigating practices. Although we did not quantify the practices, we noted that there were fewer instances of explicit evidence directing us towards how students analyzed/interpreted data, constructed explanations, and developed or used models. When looking at the data holistically, such as interviews alongside of wonder posters, we can see signs of some sensemaking practices.

One student had many questions about small bumps she found on leaves. She was curious as to what caused these bumps, leading her down a causeand-effect trail of thinking:

\section{- I thought you could ask the question, 'What is it?' but if you ask the question, 'What made it?' that would probably lead you to what it is. Because if you ask what made it... you'd probably figure out why they did it. Usually when you figure something, like what did it, you figure out why they did it. You can't just say, 'These things did it.' But why?"}

In this case, the student was working on constructing an explanation based on her wondering. She was working on building logic that would enable her to analyze related data to the bumps she discovered on leaves. The student was clearly working towards making sense of the phenomena she noticed. Her journal entries also indicate multiple instances during which she wondered how various natural features came to be, and her interpretation of available data. Based on this example and other instances, we determined that sensemaking practices were evident within the wonder-framed nature study, but that further structuring could have taken these science practices further. For example, the teacher could have asked the class to collect a sufficient amount of data, and then provide resources or tools to enable the students to make sense of their data.

\section{Critiquing Practices}

According to McNeill et al. (2018), the critiquing practices involve students evaluating scientific claims or representations as well as communicating their own information. Within our study, there was significant evidence of students engaging in the critiquing practices, especially obtaining and communicating information. Students had to determine how to present their wonder poster, which included their wonder question and an investigative plan. In the interview groups, many students discussed this particular portion of the project:
- When we built the poster, we had to think what is going to be on the poster. When we delivered our speech, it was at the Wonder Fair.

\section{- All the people that were there. It was kind of hard talking to all the people.}

We also noted that students who worked in groups had multiple opportunities to evaluate their peers' thinking process and to determine how others sought to determine information. This shows that some students engaged in critiquing processes, starting with the question they followed and ending with the information they chose to present.

\section{- It was hard because $B$ and $P$ had different ideas. And we had to all think about one idea when everybody had a different one.}

\section{- It was kind of hard to think about it, because we all had different opinions about stuff. So, we had to agree on something.}

The critiquing practices only seemed to occur within certain student groups, mainly those that had disagreements that required students to defend their thinking and offer clear explanations. This presented a challenge for some students, leading us to consider our second research question on how students engaged with the science practices.

\section{Emergent Themes Connecting the Science Practices}

Our second research question involved understanding how elementary students engage with the science practices through a wonder-framed nature study. There were four main themes that emerged through our thematic analysis, each providing insight into the experiences of the students within the study.

\section{Joy}

There seems to be little attention given to joy across most educational contexts and in particular with regards to the goals we set for students. A cursory key word search of the NGSS standards documents will result in zero mentions of joy but will reveal thirty-three pages of links related to engineering. This simply articulates what we value when looking at curricular and pedagogical goals. Interestingly, this was a feature that continually arose in our discussions, writing, and interviews with students throughout their engagement with wonder. Joy was not necessarily a goal with which we started this project, but continually elements of 'joy' emerged during analysis. The descriptions of joy typically arose as students described the processes they used 
throughout the wonder-framed experiences and these were seen across all interview groups. Wondering was a catalyst for joyful engagement with the world as highlighted by these two excerpts taken from two separate interview groups.

- Well, I thought it was pretty nice, because it was fun. And we could see whatever nature, whatever we wondered about, we could just right it down, draw a picture.

\section{- Again, it was really fun, those were some of my favorite parts of the day.}

As researchers and teachers, we point to the importance of joy as a means to build and sustain interest in any learning journey. The freedom to follow their interests seemed to be the main factor that drove students to articulate their joy. The key is that they were asked to describe the process they utilized in their wonder pursuits and invariably they described some element of joy involved in that process. As another example, three students hurriedly talked over one another to describe notions of joy that were connected to making sense of their wonders and how they might answer their questions.

Student 1: Yeah, I liked making it and wondering about a bunch of things. Like, what is this? Or, how to do things to this?

Student 2: I think it was fun finding out and trying to do and trying to find out what we should do. And coming up with all the examples.

\section{Student 3: That was fun!}

In many instances, teachers (particularly in elementary contexts) worry that if students do not get answers right away that they will become frustrated and give up on the content. However, the students in the following focus group described that figuring something out was a joyful part of the process.

- Well, like, kind of like getting it all set up, and like writing all the stuff down. It was more fun, to like, figure it out.

Scientists over the years have described similar joy in the process of science and the excitement garnered through the work involved in collecting data, hypothesizing, and solving mysteries, yet this is rarely the focus in most school science settings.

\section{Community}

In prior work with wonder and pre-service teacher educators, Gilbert and Byers (2020) articulated that building classroom community was an unintended consequence of investigating and sharing wonders with classmates. This finding also emerged in this elementary context as wonder enabled students to make connections not just between classmates, but with family members. This student engaged with her father as she shared wonders at home.

- Um, well, when I shared it with my dad, when I would ask him, when I would say one of my questions, then he would lead that with like another question. So then we just kind of sat around for like an hour just going through all my questions, and then they would answer with a question, and then I would answer that question, and then they would give me another question.

This can be a time that children are learning to express their thinking and this offered an interesting avenue for dialogue within this student's family. Consequently, it provided an opportunity to make sense of her thinking, while also building connections with her father.

This sense of connection also permeated the classroom context, where students worked together on identifying and working through their wonders and then presenting at the wonder fair.

\section{- I liked doing that because you get stronger friends with the person you did it with.}

The key is the vulnerability that is shared among students as they have to put the ideas that they are trying to figure out into the world and discuss them with others. The sharing of thoughts, possibilities, and the not-knowing served to build connection between and across the classroom community. This continued during the wonder fair as described by the following student:

- The poster was pretty fun. Um, because, it was like, it was fun to tell people about what we thought. And they would come by and start wondering about it, and it was cool to see how they would wonder about it.

The wondering became the currency of connection in the classroom, and there was an 
inherent freedom for how different people might envision the same data. This speaks to the enactment of a constructivist learning space that highlights the social nature of both learning and science itself.

\section{Autonomy}

Another comprehensive theme that emerged from the interview data was the idea of autonomy, a way in which students engaged in the science practices. As previously mentioned, autonomy-supportive instruction was a key theoretical framework for this study; we were intentional about giving students choices and freedoms within their wonder experiences. Students noticed this freedom and commented on how it impacted their engagement in the wonder-framed nature study.

\section{- I like the freedom that we were given.}

\section{- It was fun because we could pick whatever we want.}

As previously mentioned, this freedom of choice was closely connected to the joy that students experienced throughout the project. It is apparent through the data that having autonomy was an important part of the science practices and that students appreciated the freedom to make their own decisions.

Other students, however, shared that they desired even more autonomy, particularly when it came to some of the structured choices. When describing what would have made the wonder investigative process even better, one student stated that she wished that multiple wonders could have been included, rather than simply picking one. In response to an interview question about what the teachers could have done differently, she stated:

\section{- You have a full poster with tons of different wonders you had. You can write on the bottom some ways you figured them out.}

In addition to some students desiring more autonomy, a few students perceived structure or parameters to the work that were self-imposed, not put in place by the educator. One student mentioned that he had to include three questions during each wonder journal, which was not part of the instructions the teacher had stated. Even though students desired freedom of choice, it is interesting to note that many wished for a greater level of autonomy or perceived of more structure than there truly was.
The concept of time is closely related to the theme of autonomy and student choice. In all of the student focus groups, issues concerning time were brought up, and students seemed to understand that the wonder-framed nature study took a significant amount of time. A great majority of students expressed that they wished to have more time to work on some aspect of the project. Those who stated that more time would have made the project even better seemed interested in specifically having more class periods to work on the final product.

\section{Challenges}

Throughout the wonder-framed nature study, students experienced many successful moments but also a significant level of difficulties which they had to address. Thus, in response to our second research question, students engaged in the science practices with meaningful challenges. As previously mentioned, lack of time seemed to a be difficulty that students expressed. Because they had a great deal of freedom, students had to manage their own work and engagements. However, there were still some teacher-given structures within the wonder-framed nature study, which meant that a few students felt rushed to finish. Engaging in the science practices can be challenging when given time constraints. We suggest that more time can be helpful for students, yet that professional scientists often do experience time limitations.

Another challenge that students mentioned was the collaborative nature of the project or their own regret at choosing to work alone. Students had the choice as to whether they would be participating individually, with a partner, or in a larger group. The students were encouraged to think about this before making their decision. Towards the end of the wonder-framed nature study, some students expressed that they wished they were able to change their choice.

\section{- I didn't really want to do it alone.}

A few students stated that they wished they had someone to work with during the communication portion of the project, suggesting that they preferred to be with another person while sharing or defending their work. Yet the students also recognized challenges in working with a partner or within a group.

- I would probably do the wonder fair by myself because then it's not stressful to get with somebody, to get the perfect time to do this together. 
- And that is why I always work alone... It just gets too crazy and people start fighting.

Although we never observed significant arguments between students working in teams, we did note that students had challenges coming into agreement on certain decisions, involving them more heavily in science practice seven, engaging in argument from evidence (NGSS, 2013). Whether working individually or with their peers, enacting the science practices can be challenging for different reasons, compelling students to develop important skills.

The final challenge that emerged during our data analysis was the difficulty that students had with portions of science practice eight, namely communicating their findings. Some students expressed that speaking in front of others was difficult or stressful. Other students explained that it became tiresome repeating their wonder project multiple times when they were set up in stations similar to a science fair. We noted that the communication portion of the science practices seemed to bring stress to some students who were concerned about how to adequately communicate their wonder.

- Sometimes I got a little nervous when like people came and were asking tons of questions. - It was kind of hard talking to all the people.

\section{- You actually had to get your thoughts into words, which I think is hard sometimes.}

Despite these challenges, the students also repeatedly reported that their favorite part of the wonder-framed nature study was the end, during which they communicated their work. As part of the project, students also created posters to visually display their scientific processes. Many students commented on how they enjoyed designing the poster to communicate their investigation. Students appreciated hearing and seeing the wonderings of their peers.

\section{- I like seeing how everybody had different wondering things and stuff.}

\section{- I like to show people the wonder in the wonder fair because a lot - people came with different wonders.}

The appreciation of other people's wonders relates back to the idea of community addressed in an earlier section. Despite the challenges of time constraints, working alone or with others, and effectively communicating, students had overall very positive things to say about the wonder-framed nature study. We posit that when students engage in science practices, they will face challenges, but these difficulties are an inherent part in doing what professional scientists do.

\section{DISCUSSION AND IMPLICATIONS}

Our study's purpose was to explore the science practices through the viewpoint of students engaged in a wonder-framed nature study. Both research questions were answered and described in the findings section above. The data collected from student interviews, nature journals, and wonder fair projects indicate that wonder is an authentic and valuable route towards the implementation of science practices within an elementary school setting.

The connection to joy within this study cannot be understated as it is often cited by scientists as what drives the hard work of scientific studies. We agree with Feynman (1999) who posits that fun so often gets ignored in the process of engaging with science practices intended to find solutions:

Another value of science is the fun called intellectual enjoyment which some people get from reading and learning and thinking about it, and which others get from working in it. This is a very real and important point and one which is not considered enough by those who tell us it is our social responsibility to reflect on the impact of science on society (p. 143).

Feynman (1999) sees the crux of a problem that yes, science is important to larger society, but the ability for those processes to provide joy to scientific pursuits is rarely considered. This is reified in school contexts as the joy is typically lost in the rush toward meeting standards and the continual measuring of incremental progress toward content specific facts. Within our wonder-framed nature study, students displayed a considerable amount of joy and regularly commented on how much fun the experience was. This joy was also closely connected to the autonomy they experienced. Using the framework of autonomysupportive instruction empowered students to have the freedom to make their own choices. We suggest that the freedom and joy evident within this study worked hand-in-hand as students engaged in the science practices.

In reference to community, the centrality of wonder supported students to build collaborative connections through playful thinking/possibilities. Glaveneau (2020) argued that wondering can be 
most effective when shared and likens it to play that is an essential part of learning and human social development:

If it takes two (or more) persons or roles to play, it certainly does as well to wonder. In adopting a meta-position that allows us to see reality as multiple and our perspective as one among many, we necessarily refer to the perspective of other people and the way reality appears to them. The playful element in exploring these various possibilities comes from approaching the same situation from different perspectives and allowing ourselves to experiment with them freely and openly (p. 118).

This came through in our work and highlights one of the key attributes in building a community of learners in science or otherwise. It was in these wondrous playful spaces that children could try on ideas and thinking much like those taken on in play. It was also within these spaces of play that the students faced challenges that stretched their thinking as scientists and as humans. Within the wonder-frame nature study, the students dealt with decisions and issues like time management, collaboration, and communication, all which are an inevitable part of doing science. Important directions for future research efforts regarding wonder and classrooms should consider the conditions necessary for wonder to be evoked in children. This includes the essential decision-making and construction of experiences that develop both the ability and willingness for children to utilize wonder in school contexts.

This study suggests that using wonder within the classroom has many possibilities for the science practices. Although our research was situated within a private school, there are many components we feel could be easily adapted into public school setting without detracting from state-mandated standards. Additionally, we propose that future research investigate a similar wonder-framed nature study within different environments, not only a comparable elementary public school, but also high school and informal education locations.

In spite of recent NGSS reforms regarding how students engage authentically with the science practices, there is inconsistent implementation within the classroom setting (Kang et al., 2018; Merritt et al., 2018). This study investigated how students experience the science practices through a wonder-framed nature study, illuminating the possibilities of wonder within an elementary science setting. The specific skills and knowledge that students use to engage with the science practices equips them to understand the vast range of approaches that can be used to investigate and make sense of the world (NGSS, 2013). Wonder is one such approach. For teachers, wonder can be a way to authentically incorporate the science practices. As a student from our study commented, wonder can "help open up your mind, get ready for the world, and help you figure out answers on your own."^

\section{REFERENCES}

Antink-Meyer, A., \& Meyer, D. (2016). Science teachers' misconceptions in science and engineering distinctions: Reflections on modern research examples. Journal of Science Teacher Education, 27, 625-647. https://doi.org/10.1007/s10972-0169478-z

Alley, K. M. (2019). Fostering middle school students' autonomy to support motivation and engagement. Middle School Journal, 50(3), 5-14. https://doi.org/10.1080/00940771.2019.1603801

Arias, A. M., \& Davis, E. A. (2016). Making and recording observations: When done well, observations can serve as evidence when engaging in science practices. Science and Children, 58(8), 54-60. https://www.jstor.org/stable/i24721642

Baker, J., \& Goodboy, A. (2018). The choice is yours: The effects of autonomy-supportive instruction on students' learning and communication.

Communication Education, 68, 1-23. https://doi.org/10.1080/03634523.2018.1536793

Benedict-Chambers, A., \& Fortner, T. (2019). The right kind of questions. Science and Children, 56(9), 5057. https://doi.org/10.2505/4/sc19_056_09_50

Braun, V., \& Clarke, V. (2006). Using thematic analysis in psychology. Qualitative Research in Psychology, 3(2), 77-101. https://doi.org/10.1191/1478088706qp063oa

Bybee, R. W. (2014). NGSS and the next generation of science teachers. Journal of Science Teacher Education, 25, 211-221. http://dx.doi.org/10.1007/s10972-014-9381-4

Cherbow, K., McKinley, M. T., McNeill, K. L., \& Lowenhaupt, R. (2020). An analysis of science instruction for the science practices: Examining coherence across system levels and components in current systems of science education in K-8 schools. Science Education, 104(3), 446-478. https://doi.org/10.1002/sce.21573

Duschl, R. A., \& Bybee, R. W. (2014). Planning and carrying out investigations: An entry to learning and to teacher professional development around NGSS science and engineering practices. International Journal of STEM Education, 1(1), 12. https://doi.org/10.1186/s40594-014-0012-6

Engle, R.A., \& Conant, F.R. (2002). Guiding principles for fostering productive disciplinary engagement: Explaining an emergent argument in a community of learners classroom. Cognition and Instruction, 
20, $399-483$.

https://doi.org/10.1207/S1532690XCI2004_1

Feynman, R. (1999). The value of science. In J. Robbins (Ed.), The pleasure of finding things out: The best short works of Richard Feynman (pp. 141-151). Perseus/Helix Books.

Forbes, A., \& Skamp, K. (2014). "Because we weren't actually teaching them, we thought they weren't learning": Primary teacher perspectives from the My Science initiative. Research in Science Education, 44(1), 1-25. https://doi.org/10.1007/s11165-013-9367-9

Gilbert, A. (2020). Pathways to wonder-infused practice: Investigating the transition from preservice to in-service teacher. In A. Schinkel (Ed.) Wonder, education, and human flourishing (pp. 212-236). Amsterdam: Vrije University Press.

Gilbert, A. \& Byers, C. (2017). Wonder as a tool to engage preservice elementary teachers in science learning and teaching. Science Education. 101(6), 907-928. https://doi.org/10.1002/sce.21300

Gilbert, A., \& Byers, C.C. (2020). Enacting wonderinfused pedagogy in an elementary science methods course. Innovations in Science Teacher Education, 5(1). https://innovations.theaste.org/enactingwonder-infused-pedagogy-in-an-elementaryscience-methods-course/

Glăveanu, V. P. (2020). Wonder: The extraordinary power of an ordinary experience. Bloomsbury Academic.

Hadzigeorgiou, Y. (2012). Fostering a sense of wonder in the science classroom. Research in Science Education, 42(5), 985-1005. https://doi.org/10.1007/s11165-011-9225-6

Hadzigeorgiou, Y. (2014). Reclaiming the value of wonder in science education. In K. Egan, A. Cant, \& G. Judson (Eds.), Wonder-Full education: The centrality of wonder in teaching, and learning across the curriculum (pp. 40-65). Routledge.

Hadzigeorgiou, Y. (2016). Imaginative science education: The central role of imagination in science education. Springer International.

Hadzigeorgiou, Y. (2020). Wonder: Its nature and its role in the learning process. In A. Schinkel (Ed.) Wonder, education, and human flourishing (pp. 185-212). Amsterdam: Vrije University Press.

Jang, H., Reeve, J., \& Deci, E. L. (2010). Engaging students in learning activities: It is not autonomy support or structure but autonomy support and structure. Journal of Educational Psychology, 102(3), 588-600. https://doi.org/10.1037/a0019682

Johnson, R. B., \& Christensen, L. (2014). Educational research: Quantitative, qualitative, \& mixed approaches (5th ed.). Sage Publications.

Kang, E. J. S., Donovan, C., \& McCarthy, M. J. (2018). Exploring elementary teachers' pedagogical content knowledge and confidence in implementing the NGSS science and engineering practices. Journal of
Science Teacher Education, 29, 9-29.

https://doi.org/10.1080/1046560X.2017.1415616

Kawasaki, J., \& Sandoval, W. A. (2019). The role of teacher framing in producing coherent NGSSaligned teaching. Journal of Science Teacher Education, 30(8), 906-922. https://doi.org/10.1080/1046560X.2019.1657765

Kawasaki, J., \& Sandoval, W. A. (2020). Examining teachers' classroom strategies to understand their goals for student learning around the science practices in the Next Generation Science Standards. Journal of Science Teacher Education, 31(4), 384400.

https://doi.org/10.1080/1046560X.2019.1709726

Kelley, T. R., Geoffery, K. J., Holland, J. D., \& Han, J. (2020). Increasing high school teachers self-efficacy for integrated STEM instruction through a collaborative community of practice. International Journal of STEM Education 7, 1-13. http://dx.doi.org/10.1186/s40594-020-00211-w

Lowell, B. R., Cherbow, K., \& McNeill, K. L. (2021). Redesign or relabel? How a commercial curriculum and its implementation oversimplify key features of the NGSS. Science Education, 105(1), 5-32. https://doi.org/10.1002/sce.21604

McNeill, K. L., Katsh-Singer, R., \& Pelletier, P. (2015). Assessing science practices: Moving your class along a continuum. Science Scope, 39(4), 21-28. http://digital.nsta.org/publication/?i=279817\&arti cle_id $=2318459$ \&view $=$ articleBrowser

McNeill, K. L., Lowenhaupt, R. J., \& Katsh-Singer, R. (2018). Instructional leadership in the era of the NGSS: Principals' understandings of science practices. Science Education, 102(3), 452-473. https://doi.org/10.1002/sce.21336

Merriam, S. B., \& Tisdell, E. J. (2016). Qualitative research: A guide to design and implementation. John Wiley \& Sons.

Merritt, E. G., Chiu, J., Peters-Burton, E., \& Bell, R. (2018). Teachers' integration of scientific and engineering practices in primary classrooms. Research in Science Education, 48, 1321-1337. https://doi.org/10.1007/s11165-016-9604-0

Milne, I. (2010). A sense of wonder, arising from aesthetic experiences, should be the starting point for inquiry in primary science. Science Education International, 21(2), 102-115. http://www.icaseonline.net/sei/june2010/p4_ian.p df

National Science Teaching Association. (2014). Science and Engineering Practices.

https://ngss.nsta.org/PracticesFull.aspx\#: :text=T he $\% 20$ practices $\% 20$ describe $\% 20$ behaviors $\% 20$ tha t,and $\% 20$ build $\% 20$ models $\% 20$ and $\% 20$ systems.

Next Generation Science Standards. (April, 2013). Appendix F-Science and Engineering Practices in the NGSS.

https://www.nextgenscience.org/sites/default/file s/Appendix $\% 20 \mathrm{~F} \% 20 \% 20$ Science $\% 20$ and $\% 20$ Engi 
neering $\% 20$ Practices $\% 20$ in $\% 20$ the $\% 20$ NGSS $\% 20$ \%20FINAL\%20060513.pdf

Nyman, M., \& St. Clair, T. (2016). A geometric model to teach nature of science, science practices, and metacognition. Journal of College Science Teaching, 45(5).

https://doi.org/10.2505/4/jcst16_045_05_44

Pasley, J. D., Trygstad, P. J., \& Banilower, E. R. (2016, April). Towards Engagement with the Science and Engineering Practices for All Students. [Paper Presentation] 2016 NARST Annual International Conference. Baltimore, MD. http://www.horizonresearch.com/horizonresearchwp/wpcontent/uploads/2016/04/SCIOPS-2016-NARSTPaper.pdf

Reeve, J., Vansteenkiste, M., Assor, A., Ahmad, I., Cheon, S., Jang, H., Kaplan, H., Moss, J., Olaussen, B., \& Wang, C. (2014). The beliefs that underlie autonomysupportive and controlling teaching: A multinational investigation. Motivation \& Emotion, 38(1), 93-110. https://doi.org/10.1007/s11031013-9367-0

Trotman, D. (2014). Wow! What if? So what?: Education and the imagination of wonder:

Fascination, possibilities and opportunities missed. In K. Egan, A. Cant, \& G. Judson (Eds.). Wonder-Full education: The centrality of wonder in teaching, and learning across the curriculum (pp. 22-39). Routledge.

Washington, H. (2019). A Sense of Wonder towards Nature: Healing the Planet through Belonging. New York: Routledge.

Wilson, E.O. (2013). Letters to a young scientist. Liveright. 